\title{
PENGARUH OPENNESS DAN ENTREPRENEURIAL SELF- EFFICACY TERHADAP ENTREPRENEURIAL INTENTION DIMODERASI ENTREPRENEURSHIP EDUCATION DAN GENDER
}

\author{
Andi Wijaya ${ }^{1}$ \\ Universitas Tarumanagara \\ andiw@fe.untar.ac.id \\ Agustin Ekadjaja ${ }^{2}$ \\ Universitas Tarumanagara \\ agustine@fe.untar.ac.id \\ Cindy Geovanny ${ }^{3}$ \\ Universitas Tarumanagara \\ Diterima 09 Februari 2021 \\ Disetujui 25 Mei 2021
}

\begin{abstract}
The purpose of this study was to determine the effect of openness to experience and entrepreneurial self-efficacy on entrepreneurial intention and examine the moderating role of entrepreneurship education and gender on the influence between entrepreneurial selfefficacy and entrepreneurial intention. The sample in this study was obtained by crosssectional study and purposive sampling method using a questionnaire and obtained a sample of 104 students at one university in West Jakarta. The results of this study indicate that openness to experience has a positive and insignificant effect on entrepreneurial intention, entrepreneurial self-efficacy has a positive and significant effect on entrepreneurial intention, entrepreneurship education has a positive and insignificant effect as a moderating variable on the effect of entrepreneurial self. -efficacy on entrepreneurial intention and gender have a positive and insignificant effect as moderating variables on the effect of entrepreneurial self-efficacy on entrepreneurial intention. Students who have high curiosity and openness tend to be interested in trying new things to build a business and this does not depend on gender. Universities through their teaching staff are required to be able to inspire in creating individual entrepreneurial self-efficacy, through the task of making business models \& direct business practices will provide an overview of the business world to strengthen students' intentions to become entrepreneurs and present teachers who are business practitioners judged to be able to act as role models. For students to emulate and thus will strengthen the individual's belief in entrepreneurial abilities
\end{abstract}

Keywords: Openness to Experience; Entrepreneurial Self-Efficacy; Entrepreneurship Education; Gender; Entrepreneurial Intention 


\section{PENDAHULUAN}

\subsection{Latar Belakang}

Pada tiap negara keberadaan entrepreneur dianggap sebagai suatu hal yang sangat penting bagi kemajuan suatu bangsa, hal ini dikarenakan entrepreneur berperan besar dalam pendapatan dan pembangunan ekonomi endogen suatu negara sehingga dapat bersaing secara global (Mustaqim, 2019). Namun demikian, dilansir dari data Global Entrepreneurship Indeks pada tahun 2018, Indonesia berada pada urutan ke 94 dari 137 negara di dunia, dimana peringkat ini terbilang sangat rendah. Menurut mantan Menko Polhukam Wiranto, untuk menjadi negara maju setidaknya harus memiliki entrepreneur dengan jumlah rasio lebih dari $14 \%$ rasio penduduk di suatu negara. Indonesia sendiri rasio entrepreneur ini hanya mencapai angka 3,1\% dari keseluruhan penduduk sehingga masih sangatlah jauh tertinggal (Ristianto, 2019). Hal yang menyebabkan masyarakat enggan berusaha dapat disebabkan belum pengalaman, melihat kegagalan orang lain, merasa belum mampu, takut tidak dapat membagi waktu, adanya ketidakpastian, tidak memiliki motivasi (idntimes.com, 2020). Tanpa adanya pemahaman yang benar terhadap entrepreneur intention, maka sulit bagi masyarakat untuk menjadi entrepreneur. Hal ini penting dikarenakan, dalam kenyataannya entrepreneurial intention berperan penting sebagai presekutor dan membantu dalam pengambilan keputusan untuk melakukan tindakan entrepreneurial bagi seorang entrepreneur (Liñán dan Chen, 2009).

Openness to experience diidentifikasi mampu mendorong seseorang untuk berpikir secara terbuka, dengan sudut pandang yang berbeda sehingga membuat seorang individu kaya akan experience. Openness to experience merupakan hal yang penting bagi seorang entrepreneur dimana hal ini berperan dalam kemampuannya untuk melihat dan menyadari peluang yang ada (Farrukh et al., 2017). Penelitian Mei et al. (2017) mengungkapkan bahwa openness to experience merupakan hal yang menentukan intention dari seorang individu untuk menjadi seorang entrepreneur. Karakteristik lainnya yang juga berperan penting adalah entrepreneurial self-efficacy. Entrepreneurial self-efficacy merupakan self-efficacy dalam konteks entrepreneur yang lebih luas dengan perbedaan yaitu juga diperlukannya sisi kreatifitas dan inovasi dalam membangun suatu bisnis baru (Newman et al., 2019). Seorang entrepreneur dengan self-efficacy tinggi memiliki kepercayaan diri dengan kemampuannya sendiri untuk menghadapi tugas yang sulit untuk dilakukan, sehingga memiliki tekad dan intention yang lebih kuat untuk menjadi entrepreneur. Adapun entrepreneurship education diketahui mampu memperkuat dan memberikan dampak positif antara entrepreneurial self-efficacy dan entrepreneurial intention (Fietze dan Boyd, 2017a; Saeed et al., 2015). Penelitian Shahab et al. (2019) mengungkapkan bahwa bakat sebagai entrepreneur bukanlah bawaan dari lahir. entrepreneurship education merupakan suatu aspek penting yang berpengaruh terhadap entrepreneurship dan dapat mendorong timbulnya kepercayaan diri \& intention individu untuk menjadi seorang entrepreneur. Melalui entrepreneurship education seorang individu akan mendapatkan gambaran dan pembelajaran yang dibutuhkan untuk membangun sebuah bisnis, sehingga individu akan memiliki kepercayaan diri yang lebih pada kemampuan entrepreneurialnya untuk membangun sebuah bisnis dan dengan demikian akan memiliki intention yang lebih kuat untuk menjadi seorang entrepreneur. Pola pikir (mindset) sebagian besar masyarakat Indonesia adalah bahwa tujuan sekolah/kuliah adalah untuk menjadi karywan bukan untuk menjadi seseorang yang mempunyai mental wirausaha (pendidikanekonomi.com, 2014). Apabila dilihat dari sisi gender dalam kaitan dengan intensi berwirausaha, penelitian dari Hassan et al. (2020) menyimpulkan pengaruh self-efficacy pada kecenderungan untuk melakukan tindakan entrepreneurial akan bervariasi tergantung pada gender dari individu tersebut.

Berbeda dengan penelitian Murugesan dan Jayavelu (2017), yang menyimpulkan gender 
tidak memoderasi pengaruh antara self-efficacy dan entrepreneurial intention. Penelitian ini juga didukung oleh Díaz-Garcíadan Jiménez-More no (2010) yang menyimpulakan tidak ditemukan bukti gender memoderasi pada pengaruh antara Self-Efficacy dan Entrepreneurial Intention. Penelitian Ahmed, Khattak, dan Anwar (2020) menyimpulkan openness to experience tidak memiliki pengaruh terhadap entrepreneurial intention. Penelitian yang dilakukan oleh Shahab, Chengang, Arbizu, dan Haider (2019), menyimpulkan entrepreneurship education tidak memiliki pengaruh yang signifikan sebagai variabel moderasi pada pengaruh antaraentrepreneurial self-efficacy dan entrepreneurial intention.

Berdasarkan banyak penelitian sebelumnya terdapat perbedaan hasil yang diperoleh sehingga menimbulkan gap antar hasil penelitian tersebut. Hal ini menjadi sesuatu yang menarik untuk dilakukan penelitian dengan tema ini untuk memberikan kontribusi baru kedepannya.

\subsection{Tujuan Penelitian}

1. Untuk menguji secara empiris pengaruh openness to experience terhadap entrepreneurial intention.

2. Untuk menguji secara empiris pengaruh entrepreneurial self-efficacy terhadap entrepreneurial intention.

3. Untuk menguji secara empiris apakah entrepreneurship education memoderasi pada pengaruh entrepreneurial self-efficacy terhadap Entrepreneurial Intention.

4. Untuk menguji secara empiris apakah gender memoderasi pada pengaruh entrepreneurial self-efficacy terhadap entrepreneurial intention.

\subsection{Kajian Teori}

Planned behavior theory merupakan peningkatan dari reasoned action theory. Teori reasoned action theory menyatakan bahwa niat untuk melaksanakan perbuatan tertentu diakibatkan oleh dua alasan, yaitu norma subjektif dan sikap terhadap perilaku (Fishbein dan Ajzen, 1975). Beberapa tahun kemudian, Ajzen (1988) menambahkan satu faktor yaitu kontrol perilaku persepsian individu atau perceived behavioral control. Keberadaan faktor tersebut mengubah reasoned action theory menjadi Planned behavior theory. Patiro dan Budiyanti (2016), mengungkapkan Teori Planned Behavior merepresentasikan perilaku yang sebenarnya dari seorang individu yang merupakan fungsi tertimbang dari kontrol atas perilaku individu dan niat yang mendasari suatu perilaku dilakukan oleh individu. Albert Bandura adalah pencetus teori self efficacy. Bandura (dalam Indarti, 2008) mendefinisikan efikasi diri sebagai kepercayaan seseorang atas kemampuan dirinya untuk menyelesaikan suatu pekerjaan, atau dengan kata lain, kondisi motivasi seseorang yang lebih didasarkan pada apa yang mereka percaya daripada apa yang secara objektif benar. Maddux (dalam Snyder dan Lopez, 2002) mengatakan bahwa selfefficacy didefinisikan dan diukur bukan sebagai suatu sifat tetapi sebagai keyakinan tentang kemampuan untuk mengkoordinasikan ketrampilan dan kemampuan untuk mencapai tujuan yang diinginkan dalam domain dan keadaan tertentu.

Model entrepreneurial menyatakan seringkali sebuah tindakan entrepreneurial dilakukan dengan adanya intention. Five-factor (Big Five) model (FFM), merupakan lima dimensi kepribadian luas yang mewakili hampir sebagian besar ciri kepribadian. Kelima kepribadian tersebut yaitu conscientiousness, openness to experience, emotional stability, extraversion dan agreeableness (McShane \& Von Glinow, 2018). Penelitian ini berfokus pada salah satu dari kelima kepribadian tersebut, yaitu openness to experience. Hal ini mengacu pada penemuanpenemuan sebelumnya yang menyatakan bahwa openness to experience adalah salah satu kepribadian yang paling berperan untuk terbentuknya intention, sehingga penting untuk dimiliki oleh seorang entrepreneur (Şahin et al., 2019; Farrukh et al., 2017). Individu dengan 
openness to experience tinggi akan memiliki rasa penasaran yang tinggi dan terbuka pada hal asing, sehingga dapat dikatakan adalah seseorang yang kreatif, imajinatif, dan inovatif, serta memiliki intention lebih yang mendorongnya memilih karir sebagai entrepreneur.

Abdullah (2019) mengungkapkan bahwa dalam teori kognitif sosial, pencapaian manusia yang terwujud melalui usaha kolektif, sama seperti pencapaian melalui usaha individual. Persepsi terhadap self-efficacy dalam teori sosial kognitif menempati peran yang penting, dikarenakan keyakinan efficacy dapat mempengaruhi kemampuan manusia beradaptasi pada perubahan. entrepreneurial self-efficacy seringkali digunakan untuk mengukur besarnya keyakinan entrepreneur terhadap diri mereka dalam kaitannya untuk membangun bisnis. Mortan et al. (2014) mengungkapkan, semakin individu yakin pada kompetensinya, maka semakin individu akan memiliki Intention yang lebih kuat untuk memilih menjadi seorang entrepreneur.

Fietze dan Boyd (2017) menyatakan, melalui program entrepreneurship education individu dapat meningkatkan kemampuan entrepreneurialnya. Siswa yang mendapatkan pembelajaran entrepreneurship education memiliki potensi yang lebih besar untuk berhasil di dalam bisnisnya dibandingkan dengan orang tanpa adanya latar belakang pendidikan (Curth, 2015). Melalui entrepreneurship education dapat diciptakan individu yang percaya diri pada kemampuannya untuk memulai bisnis, sehingga dengan demikian seorang individu akan memiliki self-efficacy kuat yang mendorongnya untuk menjadi seorang entrepreneur.

Roof (2016) menyatakan gender memiliki makna beragam, dapat berupa pria dan wanita atau maskulin dan feminim. Macionis (2017) menyatakan budaya masyarakat adalah mengenderkan. Masyarakat cenderung memiliki stereotip negatif terhadap kaum wanita terutama dalam hal entrepreneurial karena dianggap untuk mendirikan bisnis dibutuhkan maskulinitas dan merupakan pekerjaan pria. Sebagian wanita juga berpandangan gender mereka tidak sesuai untuk mendirikan sebuah bisnis. Ketidakselarasan ini pada akhirnyamengurangi keyakinan dalam diri seorang wanita untuk dapat berhasil menjadi seorang entrepreneur, yang akhirnya berdampak pada rendahnya entrepreneurial intention wanita.

\subsection{Kaitan antara Variabel-Variabel}

\subsubsection{Kaitan antara Openness to Experience dan Entrepreneurial Intention}

Pada penelitian oleh Ettis dan Kefi (2016) diungkapkan bahwa individu dengan karakteristik serta kepribadian openness mampu meningkatkan entrepreneurial intention dari siswa. Semakin tinggi daya imajinatif dan rasa penasaran individu, maka semakin besar kecenderungannya untuk ia menjadi seorang entrepreneur. Sesuai dengan pernyataan tersebut, disimpulkan bahwa openness to experience berpengaruh positif terhadap entrepreneurial intention. Penelitian lainnya oleh Mei et al. (2017) mengungkapkan bahwa openness to experience berkaitan positif dengan daya dari individu untuk menghasilkan ide baru dan berinovasi. Dengan demikian, dikatakan bahwa openness to experience merupakan hal yang menentukan intention dari seorang individu untuk menjadi seorang entrepreneur. Penelitian dari Sahin, Karadag\&Tuncer (2019) menyimpulkan openness to experience berpengaruh positif terhadap Entrepreneurial Intention.

\subsubsection{Kaitan antara Entrepreneurial Self-Efficacy dan Entrepreneurial Intention}

Mortan et al. (2014), menyatakan bahwa individu merumuskan intention mereka untuk menjadi seorang entrepreneur dipengaruhi oleh tingginya persepsi terhadap self-efficacy. Bersamaan dengan pernyataan tersebut, ditemukan fakta yang sejalan, yaitu berdasarkan penelitian dan analisis, ditemukan hasil yang mengindikasikan pengaruh yang positif antara entrepreneurial self-efficacy dengan intention untuk menjadi seorang entrepreneur. Penelitian 
dari Farrukh, A. A., Khan, M. S. (2017) menyimpulkan entrepreneurial self-efficacy dan entrepreneurial intention. Penelitian dari Shah, Amjed, dan Jaboob (2020) menyimpulkan bahwa self-efficacy adalah prediktor signifikan dari Intentions towards Entrepreneurship.

\subsubsection{Kaitan antara Entrepreneurial Self-Efficacy dan Entrepreneurial Intention dengan Entrepreneurship Education sebagai variabel moderasi}

Hassan et al. (2020) mengungkapkan entrepreneurship education dan pelatihan entrepreneurial mempengaruhi secara positif entrepreneurial self-efficacy seorang individu, serta persepsi untuk mendirikan sebuah usaha, sehingga berperan dalam penciptaan Entrepreneurial Intention dalam diri individu. Sesuai dengan pernyataan tersebut, pada penelitian ditemukan entrepreneurship education secara positif dan signifikan mampu memoderasi pengaruh entrepreneurial self-efficacy dan entrepreneurial intention. Penelitian lainnya oleh Shahab et al. (2019) mengungkapkan bahwa bakat sebagai entrepreneur bukanlah bawaan dari lahir. entrepreneurship education merupakan suatu aspek penting yang berpengaruh terhadap entrepreneurship dan dapat mendorong timbulnya kepercayaan diri \& intention individu untuk menjadi seorang entrepreneur. Penelitian Shah, Amjed,dan Jaboob (2020) menyimpulkan entrepreneurship education memoderasi dengan memperkuatpengaruh personal attitude dan self-efficacy terhadap Intentions towards Entrepreneurship.

\subsubsection{Kaitan antara Entrepreneurial Self-Efficacy dan Entrepreneurial Intention dengan Gender sebagai variabel moderasi}

Penelitian Hassan et al. (2020) menyimpulkan pengaruh self-efficacy pada kecenderungan untuk melakukan tindakan entrepreneurial akan bervariasi tergantung pada gender dari individu tersebut. Pria cenderung lebih menunjukkan entrepreneurial intention yang lebih kuat, sedangkan wanita cenderung lebih rendah. Sejalan dengan pernyataan tersebut, pada penelitian ini ditemukan bahwa gender memoderasi secara negatif pada pengaruh entrepreneurial selfefficacy dan entrepreneurial intention. Penelitian lainnya oleh Murugesan dan Jayavelu (2017), mengungkapkan bahwa wanita cenderung jarang terlibat dalam kegiatan entrepreneurial akibat dari rendahnya entrepreneurial self-efficacy yang dimiliki. wanita sendiri jarang ditemukan melihat dirinya sendiri sebagai seorang entrepreneur, yang disebabkan stereotip negatif di dalam masyarakat bahwa entrepreneur merupakan bidang untuk pria. Penelitian Israr dan Saleem (2018) menyimpulkan gender, family background, entrepreneurial education, extraversion, agreeableness, dan openness toexperience memberikan pengaruh positif kepada Entrepreneurial intentions 


\subsection{Model Penelitian dan Hipotesis}

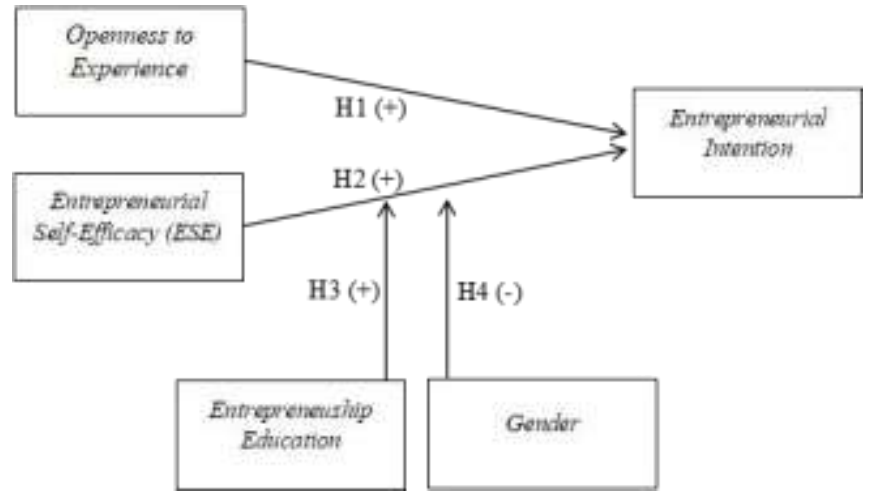

Gambar 1. Model Penelitian

Sumber: Hassan, Sallem, Anwar dan Hussain (2020)

Hipotesis dalam penelitian ini adalah sebagai berikut.

$\mathrm{H}_{1}$ : Openness to experience memiliki pengaruh yang positif dan signifikan terhadap entrepreneurial intention

$\mathrm{H}_{2}$ : Entrepreneurial self-efficacy memiliki pengaruh yang positif dan signifikan terhadap entrepreneurial intention

$\mathrm{H}_{3}$ : Entrepreneurship education memoderasi secara positif dan signifikan pada pengaruh antara entrepreneurial self-efficacy dan entrepreneurial intention.

$\mathrm{H}_{4}$ : Gender memoderasi secara negatif dan signifikan pada pengaruh antara entrepreneurial self-efficacy dan entrepreneurial intention.

\section{METODOLOGI PENELITIAN}

Desain penelitian yang digunakan adalah penelitian deskriptif, dengan metode penelitian yang bersifat kuantitatif. Lebih lanjut, penelitian memiliki tingkat intervensi minimum, dengan time horizon yang digunakan adalah cross sectional study. Populasi pada penelitian ini mencakup mahasiswa pada salah satu perguruan tinggi swasta di Jakarta Barat, alasan peneliti menggunakan universitas ini kemudahan memperoleh akses pengambilan sampel pada tempat tersebut sehingga dapat menghemat waktu, biaya, dan tenaga. Pengambilan sampel menggunakan non-probability sampling dengan teknik purposive sampling yang merupakan teknik dimana sampel dipilih atas dasar alasan karena adanya kriteria dan pertimbangan tertentu yang diberlakukan sehingga akhirnya tersisa sekelompok orang yang dianggapnya mampu untuk memberikan informasi dan memenuhi syarat yang dibutuhkan untuk menjadi sampel penelitian. Dengan teknik ini diharapkan hasil dari penelitian tidak bias dan menunjukkan hasil yang lebih representatif. Menurut Sekaran dan Boggie (2016), ukuran sampel yang layak dan ideal untuk digunakan di dalam suatu penelitian agar hasil penelitian efektif dan memenuhi persyaratan adalah ukuran sampel yang lebih besar dari 30 dan kurang dari 500 ideal digunakan untuk sebagian besar penelitian. Jumlah responden untuk kuesioner yang dibagikan, diperoleh sebanyak 104 responden. Dengan program SmartPLS 3.3.2 data tersebut diolah \& dilakukan pengujian. Pengujian terbagi atas dua, yaitu outer model dan inner model. Pada uji outer model dilakukan uji validitas dan reliabilitas. Sampel framework yang dipilih didasarkan atas pertimbangan-pertimbangan tertentu, yaitu merupakan mahasiswa yang masih aktif berkuliah hingga Semester Ganjil 2020/ 2021, mahasiswa pada jurusan manajemen di Fakultas Ekonomi dan Bisnis, mengambil konsentrasi Kewirausahaan 
Penelitian dikatakan memenuhi unsur validitas, apabila pada convergent validity diperoleh nilai $>0,7$ pada outer loadings dan nilai $>0,5$ pada average variance extracted ( $A V E$ ), serta pada discriminant validity ditunjukkan Fornell-larcker criterion yang nilai akar kuadrat dari $A V E$ setiap konstruksi reflektif lebih besar dari korelasi konstruk lainnya dan cross loading factor dengan memastikan nilai loading pada konstruk yang dituju lebih besar daripada nilai loading dengan konstruk lainnya. Sedangkan, penelitian dikatakan memenuhi unsur reliabilitas, apabila pada composite reliability diperoleh nilai antara 0,70-0,90 dan cronbach's alpha $>0,6$.

Pada uji inner model dilakukan pengujian $R$ Square untuk mengetahui kekuatan prediksi model (nilai koefisien harus $>0,25$ ), $Q$ Square melalui prosedur blindfolding untuk mengetahui seberapa baik nilai observasi (0,02 kecil, 0,15 menengah, dan 0,35 besar), dan path coefficient untuk mengetahui arah pengaruh hipotesis penelitian (berkisar antara -1 sampai dengan +1 ). Pengujian goodness of fit untuk memvalidasi model secara menyeluruh $(0,1$ kecil, 0,25 menengah, dan 0,36 besar). Uji hipotesis melalui prosedur bootstrapping untuk mengetahui pengaruh signifikansi antar variabel (signifikan bila $t$-statistics $>1,96$ dan $p$-values $<0,05$ ).

\section{HASIL DAN PEMBAHASAN}

Berdasarkan pengujian validitas yang dilakukan, pada convergent validity ditunjukkan nilai akhir setiap indikator outer loading $>0,7$ (memenuhi syarat) dan $A V E>0,5$ (memenuhi syarat) dan pada discriminant validity ditunjukkan Fornell-larcker criterion dimana akar kuadrat dari $A V E$ yang terletak secara diagonal apabila dibandingkan dengan nilai korelasi konstruk pada baris dan kolomnya merupakan nilai yang terbesar (memenuhi syarat) dan cross loading factor dimana nilai loading pada indikator dengan variabelnya lebih besar dibandingkan dengan nilai loading lainnya yang terdapat pada kolom maupun baris tersebut (memenuhi syarat). Dengan demikian, dapat disimpulkan bahwa instrumen penelitian akurat dalam mengukur konsep dan valid untuk digunakan dalam penelitian. Sedangkan, berdasarkan pengujian reliabilitas, ditunjukkan nilai composite reliability $>0,7$ (memenuhi syarat) dan cronbach's alpha > 0,6 (memenuhi syarat). Jadi penelitian terbebas dari bias dan pengukuran yang digunakan konsisten, serta reliabel untuk digunakan.

Pada pengujian diperoleh nilai $R$ Square 0,552 atau 55,2\% (memenuhi syarat $>0,25$ ) yang artinya variabel entrepreneurial intention mendapatkan pengaruh sebesar 55,2\% dari keempat variabel. Pada pengujian $Q$ Square diperoleh nilai 0,330 (memenuhi syarat $>0$ ) yang artinya nilai observasi yang dihasilkan merupakan nilai yang moderat. Melalui pengujian path coefficient seperti yang terlihat pada tabel 1, diketahui seluruh variabel pada hipotesis memiliki pengaruh positif terhadap variabel entrepreneurial intention.

Pengujian Goodness of Fit melalui perhitungan manual diperoleh nilai GoF sebesar 0,6652. Dengan demikian, diartikan penelitian ini memiliki kecocokan yang besar $(>0,36)$. Melalui pengujian hipotesis seperti yang terlihat pada tabel 1, diketahui entrepreneurial selfefficacy memiliki pengaruh yang positif terhadap Entrepreneurial Intention atau $\mathrm{H}_{2}$ tidak ditolak ( $t$-statistics $>1,96$ dan p-values $<0,05$ ). Sedangkan pada $\mathrm{H}_{1}, \mathrm{H}_{3}$, dan $\mathrm{H}_{4}$ tidak ditemukan pengaruh yang signifikan terhadap entrepreneurial intention atau hipotesis ditolak (t-statistics $<1,96$ dan $p$-values $>0,05)$. 
Tabel 1. Pengujian Hipotesis

\begin{tabular}{|c|c|c|c|}
\hline & $\begin{array}{c}\text { Path } \\
\text { coefficient }\end{array}$ & $\begin{array}{c}\text { t-statistics } \\
(\mid \text { OSTDEV } \mid)\end{array}$ & p-values \\
\hline $\begin{array}{c}\text { ESE*EE -> } \\
\text { Entrepreneurial Intention }\end{array}$ & 0,070 & 0,655 & 0,256 \\
\hline $\begin{array}{c}\text { ESE*Gender -> Entrepreneurial } \\
\text { Intention }\end{array}$ & 0,096 & 1,064 & 0,144 \\
\hline $\begin{array}{c}\text { Entrepreneurial Self- Efficacy -> } \\
\text { Entrepreneurial Intention }\end{array}$ & 0,682 & 8,239 & 0,000 \\
\hline $\begin{array}{c}\text { Entrepreneurship Education -> } \\
\text { Entrepreneurial Intention }\end{array}$ & 0,089 & 0,897 & 0,185 \\
\hline $\begin{array}{c}\text { Gender -> Entrepreneurial } \\
\text { Intention }\end{array}$ & $-0,117$ & 1,590 & 0,056 \\
\hline $\begin{array}{c}\text { Openness to Experience - } \\
\text { Entrepreneurial Intention }\end{array}$ & 0,000 & 0,005 & 0,498 \\
\hline
\end{tabular}

\section{KESIMPULAN}

\subsection{Implikasi Manajerial}

Hasil pengujian $\mathrm{H}_{1}$ menunjukkan bahwa openness to experience memiliki pengaruh yang positif dan tidak signifikan terhadap entrepreneurial intention. Hasil penelitian ini sejalan dan didukung melalui hasil penelitian yang dilakukan oleh Mei et al. (2017), dimana ditemukan openness to experience tidak memiliki pengaruh yang signifikan terhadap entrepreneurial intention. Hal ini dikarenakan, mahasiswa yang memiliki rasa penasaran dan keterbukaan yang tinggi cenderung tertarik untuk mencoba berbagai hal baru, yang membuatnya menjadi tidak dapat berfokus pada satu hal seperti misalnya pada intentionnya untuk membangun bisnis dan menjadi entrepreneur.

Hasil pengujian $\mathrm{H}_{2}$ menunjukkan bahwa entrepreneurial self-efficacy berpengaruh positif dan signifikan terhadap entrepreneurial intention. Penelitian ini sejalan dan memperkuat hasil penelitian Mortan et al. (2014) dan Mei et al. (2017), dimana juga ditemukan pengaruh yang positif dan signifikan pada entrepreneurial self-efficacy terhadap entrepreneurial intention. Ketika seseorang yakin pada kemampuan entrepreneurial yang dimilikinya, mereka akan memiliki intention yang lebih kuat untuk menjadi seorang entrepreneur dan mewujudkannya dalam tindakan nyata.

Hasil pengujian $\mathrm{H}_{3}$ menunjukkan bahwa entrepreneurship education memiliki pengaruh yang positif dan tidak signifikan sebagai variabel moderasi pada pengaruh antara entrepreneurial self-efficacy dan entrepreneurial intention. Penelitian ini tidak mendukung hipotesis yang dinyatakan oleh Hassan et al. (2020). Namun, hasil penelitian ini sejalan dan didukung melalui hasil penelitian yang dilakukan oleh Shahab et al. (2019), dimana ditemukan entrepreneurship education tidak memiliki pengaruh yang signifikan sebagai variabel moderasi pada pengaruh antara entrepreneurial self-efficacy dan entrepreneurial intention. Hal ini disebabkan, Indonesia memiliki tingkat pendidikan yang terbilang rendah yang diakibatkan rendahnya kesadaran dan pemahaman akan pentingnya pendidikan terutama pendidikan entrepreneurial yang berperan dalam penciptaan intention dalam diri seorang individu untuk menjadi entrepreneur. Yang akhirnya berimbas pada tertinggalnya jumlah entrepreneur dibandingkan negara lainnya.

Hasil pengujian $\mathrm{H}_{4}$ menunjukkan bahwa gender memiliki pengaruh yang positif dan tidak signifikan sebagai variabel moderasi pada pengaruh antara entrepreneurial self-efficacy dan entrepreneurial intention. Penelitian ini tidak mendukung hipotesis yang dinyatakan oleh Hassan et al. (2020). Namun, hasil penelitian ini sejalan dan didukung melalui hasil penelitian 
yang dilakukan oleh Murugesan dan Jayavelu (2017), dimana ditemukan gender tidak memiliki pengaruh yang signifikan sebagai variabel moderasi pada pengaruh antara entrepreneurial selfefficacy dan entrepreneurial intention. Hal ini dikarenakan, seiring dengan perkembangan jaman, perbedaan gender bukan lagi menjadi penentu entrepreneurial self-efficacy yang dimiliki individu. Terlepas dari gender yang dimiliki seseorang, hal yang lebih penting adalah memiliki kemampuan dan kapabilitas entrepreneurial yang dibutuhkan yang mendukung entrepreneurial intention yang dimiliki individu.

Implikasi hasil penelitian ini bagi dunia pendidikan adalah diharapkan pihak penyelenggara pendidikan tetap memperhatikan kemampuan dari mahasiswa dalam perkuliahannya, karena mahasiswa memiliki rasa penasaran dan keterbukaan yang tinggi cenderung tertarik untuk mencoba berbagai hal baru untuk membangun bisnisnya. Hal ini dapat dilakukan melalui seminar entrepreneurial dengan menghadirkan narasumber yang telah sukses dalam membangun bisnis sehingga dengan demikian para mahasiswa akan memiliki keyakinan (self-efficacy) kuat untuk menjadi seorang entrepreneur tanpa memperhatikan gendernya. Di samping itu para pengajar diharapkan mampu menginspirasi nilai penting dalam menciptakan entrepreneurial self-efficacy mahasiswa melalui tugas membuat model bisnis yang diharapkan akan memberikan gambaran tentang dunia bisnis sehingga memperkuat intention mahasiswa untuk menjadi seorang entrepreneur.

\subsection{Simpulan}

Berdasarkan hasil analisis data diperoleh simpulan sebagai berikut:

1. Openness to experience memiliki pengaruh yang positif dan tidak signifikan terhadap entrepreneurial intention.

2. Entrepreneurial self-efficacy memiliki pengaruh yang positif dan signifikan terhadap entrepreneurial intention.

3. Entrepreneurship education memiliki pengaruh yang positif dan tidak signifikan sebagai variabel moderasi pada pengaruh antara Entrepreneurial self-efficacy dan entrepreneurial intention.

4. Gender memiliki pengaruh yang positif dan tidak signifikan sebagai variabel moderasi pada pengaruh antara entrepreneurial self-efficacy dan entrepreneurial intention.

\subsection{Keterbatasan dan saran serta diskusi}

Pada penelitian ini difokuskan pada variabel seperti openness to experience, entrepreneurial self-efficacy, entrepreneurship education dan gender, untuk itu perlu dikembangkan dengan menambah variabel lain untuk melihat faktor yang mempengaruhi entrepreneurial intention. Saran yang bagi penelitian yang akan datang adalah agar penelitian sejenis melakukan penelitian dalam jumlah sampel yang lebih luas seperti pada jurusan dan universitas lainnya dan disarankan variabel penelitian diperluas dengan menambah variabel independen lainnya agar diperoleh hasil yang lebih luas tentang faktor entrepreneurial intention, sedangkan bagi pihak penyelenggara pendidikan dapat mengadakan seminar entrepreneurial dengan menghadirkan narasumber yang telah sukses dalam membangun bisnis sehingga dengan demikian para mahasiswa akan memiliki keyakinan (self-efficacy) kuat untuk menjadi seorang entrepreneur. Pelaksana pendidikan yakni para dosen yang mampu menginspirasi dinilai penting dalam menciptakan entrepreneurial self-efficacy individu, serta melalui tugas membuat model bisnis\&praktik langsung berbisnis diharapkan akan memberikan gambaran tentang dunia bisnis sehingga memperkuat intention mahasiswa untuk menjadi seorang entrepreneur, dan menghadirkan pengajar yang merupakan seorang praktisi bisnis dinilai mampu berperan sebagai role model bagi para mahasiswa untuk dicontoh dan dengan 
demikian maka akan menguatkan keyakinan individu terhadap kemampuan entrepreneurialnya. Secara umum hasil penelitian ini mendukung apa yang telah dilakukan peneliti terdahulu walaupun terdapat beberapa perbedaan dengan penelitian terdahulu dan hal ini perlu didiskusikan. Banyak perbedaan penelitian yang membahas apakah minat berwirausaha dipengaruhi oleh gender dan inipun memiliki hasil yang berbeda. Pada negara berkembang relatif minat berwirausaha dipengaruhi oleh gender, untuk itu diperlukan penelitian lanjutan untuk membandingkannya. Hal lain yang perlu didiskusikan adalah apakah tingkat pendidikan mempengaruhi minat berwirausaha, banyak penelitan yang bertolakbelakang hasil yang diperoleh. Perlu dilakukan penelitian lanjutan tingkat pendidikan dengan minat berwirausaha secara khusus pada suatu negara (untuk negara maju dan/atau berkembang) untuk membandingkan hasil yang diperoleh dengan penelitian-penelitian sebelumnya.

\section{REFERENSI}

Abdullah, S. M. (2019). Social Cognitive Theory: A Bandura Thought Review published in 1982-2012. Journal Psikodimensia, 18(1), 85-100.

Ács, Z. J., Szerb, L. \& Lloyd, A. (2018). Global Entrepreneurship Index. Washington, D.C., USA: The Global Entrepreneurship and Development Institute.

Adekiya, A.A. \& Ibrahim, F. (2016). Entrepreneurship intention among students: the antecedent role of culture and entrepreneurship training and development. The International Journal of Management Education, 14(2), 116-132.

Ahmed, M. A., Khattak, M. S., \& Anwar, M. (2020). Personality traits andentrepreneurial intention: The mediating role of risk aversion. Journal of Public Affairs.

Ajzen, I., (1988) Attitudes, Personality, and Behavior, Dorsey Press: Chicago.

Ayalew, M.M. and Zeleke, S.A. (2018), "Modeling the impact of entrepreneurial attitude on self employment intention among engineering students in Ethiopia", Journal of Innovation and Entrepreneurship, 7(1).

Bandura A. (1997). Self Efficacy: The Exercise of Control. New York: W. H.Freeman and Company.

Christoforus Ristianto (2019) Wiranto: Syarat Negara Maju, 14 Persen Warganya Wirausahawan. (Diambil dari: www.kompas.com/21-9-2020).

Curth, A. (2015). Entrepreneurship Education: A Road to Success. Belgium: ICF Consulting Services Ltd.

Denanyoh, R., Adjei, K., \& Nyemekye, G. E. (2015). Factors that impact on entrepreneurial intention of tertiary students in Ghana. International Journal of Business and Social Research, 5(3), 19-29.

Diaz-Garcia, C., Saez-Martinez, F., \& Jimenez-Moreno, J. (2015). Evaluaci on del impacto del programa educativo 'emprendedores' en la intenci on emprendedor de los participantes. Rusc. Universities and Knowledge Society Journal, 12(3), 17-31.

Ettis, S. A. \& Kefi, M. K. (2016). Entrepreneurial Intentions amongst Tunisian Students: an Empirical Investigation Applying the Big-Five Personality Traits Theory. International Journal of Higher Education Management (IJHEM), 3(1), 49-64.

Farrukh, M., Khan, A. A., \& Khan, M. S. (2017). Entrepreneurial intentions: the role of family factors, personality traits and self-efficacy. World Journal of Entrepreneurship, Management and Sustainable Development, 13(4), 303-317. 
Fietze, S. dan Boyd, B. (2017). Entrepreneurial intention of Danish students: a correspondence Analysis. International Journal of Entrepreneurial Behavior and Research, 23(4), 656672.

Fishbein, M. \& Ajzen, I. (1975). Beliefe, Intention and Behavior: An Introductionto Theory and Research. Canada: Addison-Wesley Publishing Company.

Gupta, V.K., Turban, D.B. and Bhawe, N.M. (2008). The effect of gender stereotype activation on entrepreneurial intentions. Journal of Applied Psychology, 93(5), 1053-1061.

Gupta, V.K., Turban, D.B., Wasti, S.A. and Sikdar, A. (2009). The role of gender stereotypes in perceptions of entrepreneurs and intentions to become an entrepreneur. Entrepreneurship: Theory \& Practice, 33(2), 397-417.

Hassan, A., Saleem, I., Anwar, I., \& Hussain, S. A. (2020). Entrepreneurial intention of Indian university students: The role of opportunity recognition and entrepreneurship education. Education + Training.

Indarti, N. dan Rostiani, R. ( 2008). Intensi kewirausahaan Mahasiswa: Studi Perbandingan Antara Indonesia, Jepang dan Norwegia. Jurnal Ekonomikadan Bisnis, vol.23, No.4.

Ip, C.Y., Wu, S.-C., Liu, H.-C., \& Liang, C. (2017). Revisiting the antecedents of social entrepreneurial intentions in Hong Kong. International Journal of Educational Psychology, 6(3), 301-323.

Liñán, F., \& Chen, Y. (2009). Development and cross-cultural application of a specific instrument to measure entrepreneurial intentions. Entrepreneurship Theory and Practice, 33(3), 593-617.

Macionis, J. J. (2017). Society: The Basics. Hoboken, NJ: Pearson Education, Inc.

McShane, S. L. \& Von Glinow, M. A. (2018). Organizational Behavior. Penn Plaza, New York: McGraw-Hill Education.

Mei, H., Ma, Z., Jiao, S., Chen, X., Lv, X., \& Zhan, Z. (2017). The Sustainable Personality in Entrepreneurship: The Relationship between Big Six Personality, Entrepreneurial SelfEffificacy, and Entrepreneurial Intention in the Chinese Context. Sustainability, 9, 1-23.

Mei, H., Zhan, Z. Fong, P. S. W., Liang, T., \& Ma, Z. (2015). Planned behaviour of tourism students' entrepreneurial intentions in China. Applied Economics. 48(13), 1240-1254.

Moraes, G.H.S.M.D., Iizuka, E.S. \& Pedro, M. (2018). Effects of entrepreneurial characteristics and university environment on entrepreneurial intention. Revista de Administracao Contemporanea, 22(2), 226-248.

Mortan, R. A., Ripoll, P., Carvalho, C., \& Bernal, M. C. (2014). Effects of emotional intelligence on entrepreneurial intention and self-efficacy. Revista de Psicología Del Trabajo y de Las Organizaciones, 30(3), 97-104.

Mueller, S.L. dan Conway Dato-On, M. (2008). Gender-role orientation as a determinant of entrepreneurial self-efficacy. Journal of Developmental Entrepreneurship, 13(1), 3-20.

Murugesan, R. dan Jayavelu, R. (2017). The Influence of Big Five Personality Traits and Selfefficacy on Entrepreneurial Intention: The Role of Gender. Journal of Entrepreneurship and Innovation in Emerging Economies, 3(1), 41-61.

Mustaqim, Y. (2019). Membangun entrepreneurship dalam perspektif ekonomi syariah. Business Management Analysis Journal (BMAJ), 2(2), 58-78. 
Natalia, C. \& Rodhiah. (2019). Pengaruh Kreativitas, Edukasi Dan Efikasi Diri Terhadap Intensi Berwirausaha Dalam Generasi Z. Jurnal Manajerial dan Kewirausahaan, 1(2), 164-171.

Nathanael, D. \& Nuringsih, K. (2020). Social Support, Personality Traits, Social Innovation Mempengaruhi Intensi Kewirausahaan Sosial: Entrepreneurial Attitude Sebagai Mediasi. Jurnal Manajerial dan Kewirausahaan, 2(1), 33-42.

Newman, A., Obschonka, M., Schwarz,S., Cohen, M. dan Nielsen, I. (2019). Entrepreneurial self-efficacy: A systematic review of the literatureon its theoretical foundations, measurement, antecedents, and outcomes, and an agenda for future research. Journal of Vocational Behavior, 110, 403-419.

Patiro, S. P. S. \& Budiyanti, H. (2016). The theory of planned behavior, past behavior, situational factors, and self -identity factors drive indonesian enterpreneurs to be indebtedness. DeReMa Jurnal Manajemen, 11(1), 46-66.

http://www.pendidikanekonomi.com/2014/08/permasalahan-pendidikankewirausahaan.html\#: :text=Menurut\%20kami\%2C\%20yang\%20menjadi\%20Masalah ,seseorang\%20yang\%20mempunyai\%20mental\%20wirausaha.

Roof, J. (2016). What Gender Is, What Gender Does. London: University of Minnesota Press.

Saeed, S., Yousafzai, S.Y., Yani-De-Soriano, M. dan Muffatto, M. (2015). The role of perceived university support in the formation of students' entrepreneurial intention. Journal of Small Business Management, 53(4), 1127-1145.

Şahin, F., Karadağ, H., \& Tuncer, B. (2019). Big Five personality traits, entrepreneurial selfefficacy and entrepreneurial intention. International Journal of Entrepreneurial Behavior \& Research, 25(6), 1188-1211.

Sekaran, U. \& Bougie, R. (2016). Research method for business. United Kingdom: Wiley.

Shah, I. A., Amjed, S., \& Jaboob, S. (2020). The moderating role of entrepreneurship education in shaping entrepreneurial intentions. Journal of Economic Structures, 9(19), 1-15.

Shahab, Y., Chengang, Y., Arbizu, A. D., \& Haider, M. J. (2019). Entrepreneurial self-efficacy and intention: Do entrepreneurial creativity and education matter?. International Journal of Entrepreneurial Behavior \& Research, 25(2), 259-280.

Snyder, C.R., Lopez, S.J. (2002). Handbook of Positive Psychology. Washington DC :Oxford University Press.

Yeremia \& Widjaja, H. (2019). Prediksi Self Efficacy Dan Personality Traits Terhadap Entrepreneurial Intentions Di Kalangan Mahasiswa. Jurnal Manajerial dan Kewirausahaan, 1(3), 609-617. 